\title{
Polinomial Pembangun dari Ideal dan Dimensi dari Kode Siklik
}

\author{
Tuhfatul Janan', Mohammad Imam Utoyo ${ }^{2} \&$ Fatmawati $^{3}$ \\ ${ }^{1}$ Sekolah Tinggi Agama Islam Muhammadiyah Probolinggo \\ ${ }^{2,3}$ Departemen Matematika, Fakultas Sains dan Teknologi, Universitas Airlangga \\ ${ }^{1}$ Corresponding author: tuhfatuljanan4@gmail.com
}

\begin{abstract}
Abstrak. Dalam penelitian ini, diberikan hubungan antara ideal dan kode siklik serta sifat-sifat polinomial pembangun dari ideal dan dimensi dari kode siklik. Sifat-sifat tersebut antara lain hubungan antara polinomial pembangun dari ideal dengan polinomial monik dengan derajat terkecil di ideal, eksistensi dan ketunggalan dari polinomial pembangun dari ideal, hubungan antara polinomial pembangun dari ideal dengan pembagi monik dari $x^{n}-1$, dan hubungan antara derajat dari polinomial pembangun dari ideal dan dimensi dari kode siklik.
\end{abstract}

Kata kunci: dimensi, ideal, kode siklik, polinomial pembangun.

\section{Pendahuluan}

Teori pengkodean pertama kali ditemukan oleh Shannon pada tahun 1948 dalam jurnalnya yang berjudul "A Mathematical Theory of Communication" [4]. Teori pengkodean adalah ilmu yang mempelajari teknik dan metode transmisi data atau informasi melalui saluran komunikasi yang tidak bebas gangguan secara efisien dan akurat. Teori pengkodean telah berkembang begitu pesat dan memiliki aplikasi yang begitu luas, diantaranya minimalisasi gangguan dari perekaman $\mathrm{CD}$, transfer data dari memori ke CPU komputer atau antar CPU komputer, transaksi ATM, dan komunikasi satelit [1]. Dalam perkembangannya, kode siklik pertama kali ditemukan oleh Prange pada tahun 1957 [3]. Kode siklik merupakan bahasan penting dari teori pengkodean karena menjadi dasar dari teori pengkodean modern, seperti kode Hamming, kode Golay, kode BCH, kode Reed-Solomon, dan kode Goppa [2].

\section{Polinomial dan Ruang Vektor atas Lapangan}

Definisi 2.1 Misalkan $F$ adalah lapangan. Polinomial $f(x)=a_{0}+a_{1} x+a_{2} x^{2}+\cdots+$ $a_{n} x^{n}$ dengan $a_{i} \in F$ dan $0 \leq i \leq n$ disebut polinomial atas $F$. Himpunan semua polinomial atas $F$ dinotasikan dengan $F[x]$.

Definisi 2.2 Misalkan $f(x)=\sum_{i=0}^{n} a_{i} x^{i} \in F[x]$ adalah polinomial dengan $a_{n} \neq 0$. Bilangan bulat $n$ disebut derajat dari $f(x)$ dan dinotasikan dengan $\operatorname{deg}(f(x))$. 
Definisi 2.3 Polinomial $f(x)=\sum_{i=0}^{n} a_{i} x^{i} \in F[x]$ disebut monik jika $a_{n}=1$.

Definisi 2.4 Misalkan $f(x) \in F[x]$ dengan $\operatorname{deg}(f(x)) \geq 1$. Himpunan sisa dari pembagian semua polinomial di $F[x]$ dengan $f(x)$ dinotasikan dengan $F[x] / f(x)$.

Definisi 2.5 Aturan penjumlahan dan perkalian untuk polinomial $g(x)$ dan $h(x) \in$ $F[x] / f(x)$ didefinisikan sebagai berikut :

$$
\begin{aligned}
& g(x) \oplus h(x):=g(x)+h(x) \bmod f(x), \\
& g(x) \odot h(x):=g(x) \cdot h(x) \bmod f(x) .
\end{aligned}
$$

Untuk selanjutnya, penulisan tanda " $\oplus$ " dan " $\odot "$ secara berturut-turut disederhanakan menjadi " + " dan " . ".

Contoh 2.6 Misalkan $g(x)=x^{2}+1, h(x)=x^{3}+1 \in \mathbb{Z}_{2}[x] /\left(x^{4}-1\right)$, maka $g(x)+h(x)=x^{3}+x^{2} \operatorname{dan} g(x) \cdot h(x)=x^{3}+x^{2}+x+1$.

Definisi 2.7 Misalkan $F_{q}$ adalah lapangan berhingga dengan $q$ elemen. Ruang vektor $F_{q}^{n}:=\left\{\left(v_{1}, v_{2}, v_{3}, \ldots, v_{n}\right) ; v_{i} \in F_{q}, 1 \leq i \leq n\right\}$ disebut ruang vektor dengan panjang $n$ atas $F_{q}$. Untuk selanjutnya, penulisan vektor $v=\left(v_{1}, v_{2}, v_{3}, \ldots, v_{n}\right) \in F_{q}^{n}$ disederhanakan menjadi $\boldsymbol{v}=v_{1} v_{2} v_{3} \ldots v_{n} \in F_{q}^{n}$.

Contoh $2.8 \mathbb{Z}_{2}^{2}=\{(0,0),(0,1),(1,0),(1,1)\}$ adalah ruang vektor dengan panjang 2 atas $\mathbb{Z}_{2}$ dan penulisannya disederhanakan menjadi $\mathbb{Z}_{2}^{2}=\{00,01,10,11\}$. Sedangkan $\mathbb{Z}_{3}^{2}=\{(0,0),(0,1),(0,2),(1,0),(1,1),(1,2),(2,0)(2,1),(2,2)\}$ adalah ruang vektor dengan panjang 2 atas $\mathbb{Z}_{3}$ dan penulisannya disederhanakan menjadi $\mathbb{Z}_{3}^{2}=$ $\{00,01,02,10,11,12,20,21,22\}$.

\section{Kode Linier dan Kode Siklik}

Definisi 3.1 Ruang bagian dari $F_{q}^{n}$ disebut kode linier dengan panjang $n$ atas $F_{q}$.

Contoh 3.2 $C=\{000,001,010,011\}$ adalah kode linier dengan panjang 3 atas $\mathbb{Z}_{2}$ karena $C$ adalah ruang bagian dari $\mathbb{Z}_{2}^{3}$.

Definisi 3.3 Dimensi dari kode linier $C$ adalah dimensi dari $C$ sebagai ruang vektor atas $F_{q}$ dan dinotasikan dengan $\operatorname{dim}(C)$.

Teorema 3.4 Misalkan $C$ adalah kode linier dengan panjang $n$ atas $F_{q}$. Jika $\operatorname{dim}(C)=$ $k$, maka $|C|=q^{k}$. Jadi, $\operatorname{dim}(C)=k=\log _{q}|C|$. 
Bukti. Misalkan $\left\{\boldsymbol{c}_{1}, \boldsymbol{c}_{2}, \boldsymbol{c}_{3}, \ldots, \boldsymbol{c}_{k}\right\}$ adalah basis untuk $C$. Maka $C=\left\{\alpha_{1} \boldsymbol{c}_{1}+\alpha_{2} \boldsymbol{c}_{2}+\right.$ $\left.\alpha_{3} c_{3}+\cdots+\alpha_{k} c_{k}: \alpha_{1}, \alpha_{2}, \alpha_{3}, \ldots, \alpha_{k} \in F_{q}\right\}$. Karena $\left|F_{q}\right|=q$, maka terdapat $q$ pilihan untuk setiap $\alpha_{1}, \alpha_{2}, \alpha_{3}, \ldots, \alpha_{k}$. Oleh karena itu, $|C|=q^{k}$. Jadi, $\operatorname{dim}(C)=k=\log _{q}|C|$.

Contoh 3.5 Dimensi dari $C=\{000,001,010,011\}$ adalah $\operatorname{dim}(C)=\log _{2} 4=2$.

Definisi 3.6 Kode linier $C$ dengan panjang $n$ dan dimensi $k$ atas $F_{q}$ disebut kode linier $q$-ary $[n, k]$.

Contoh $3.7 C_{1}=\{000,001,010,011\}$ adalah kode linier 2-ary $[3,2]$ karena $C_{1}$ adalah kode linier dengan panjang 3 dan dimensi 2. Sedangkan $C_{2}=$ $\{0000,0001,1100,1101,1102,0002,2200,2201,2202\}$ adalah kode linier 3 -ary $[4,2]$ karena $C_{2}$ adalah kode linier dengan panjang 4 dan dimensi 2.

Definisi 3.8 Kode linier $C$ dengan panjang $n$ atas $F_{q}$ disebut kode siklik jika untuk setiap $\left(c_{0}, c_{1}, c_{2}, \ldots, c_{n-1}\right) \in C$ mengakibatkan $\left(c_{n-1}, c_{0}, c_{1}, \ldots, c_{n-2}\right) \in C$.

Contoh 3.9 $C_{1}=\{000,110,011,101\}$ adalah kode siklik 2-ary $[3,2]$ karena $C_{1}$ adalah kode linier dengan panjang 3 atas $\mathbb{Z}_{2}$ dan $000,110,011,101 \in C_{1}$. Sedangkan $C_{2}=\{0000,1010,0101,1111\}$ adalah kode siklik 2-ary $[4,2]$ karena $C_{2}$ adalah kode linier dengan panjang 4 atas $\mathbb{Z}_{2}$ dan $0000,1010,0101,1111 \in C_{2}$.

\section{$4 \quad$ Hubungan antara Ideal dan Kode Siklik}

Didefinisikan transformasi linier yang memetakan ruang vektor $F_{q}^{n}$ ke ring polinomial $F_{q}[x] /\left(x^{n}-1\right)$ sebagai berikut :

$$
\begin{aligned}
& \pi: F_{q}^{n} \rightarrow F_{q}[x] /\left(x^{n}-1\right), \text { dengan pengaitan } \\
& \left(a_{0}, a_{1}, a_{2}, \ldots, a_{n-1}\right) \mapsto a_{0}+a_{1} x+a_{2} x^{2}+\cdots+a_{n-1} x^{n-1}
\end{aligned}
$$

Teorema 4.1 Misalkan $\pi$ adalah transformasi linier yang didefinisikan pada (1). Himpunan bagian tak kosong $C$ dari $F_{q}^{n}$ adalah kode siklik jika dan hanya jika $\pi(C)$ adalah ideal dari $F_{q}[x] /\left(x^{n}-1\right)$.

Bukti. $(\Leftarrow)$ Misalkan $\pi(C)$ adalah ideal dari $F_{q}[x] /\left(x^{n}-1\right)$.

Ambil sebarang $\boldsymbol{a}, \boldsymbol{b} \in C$ dan $\alpha \in F_{q}[x] /\left(x^{n}-1\right)$. Akibatnya, $\pi(\boldsymbol{a}), \pi(\boldsymbol{b}) \in \pi(C)$ sehingga $-\pi(\boldsymbol{b}) \in \pi(C)$. Karena $\pi$ adalah transformasi linier, maka $\pi(\boldsymbol{a})-$ $(-\pi(\boldsymbol{b}))=\pi(\boldsymbol{a})+\pi(\boldsymbol{b})=\pi(\boldsymbol{a}+\boldsymbol{b}) \in \pi(C)$ dan $\alpha \pi(\boldsymbol{a})=\pi(\alpha \boldsymbol{a}) \in \pi(C)$ sehingga $+\boldsymbol{b}, \alpha \boldsymbol{a} \in C$. Oleh karena itu, $C$ merupakan kode linier. Selanjutnya, ambil sebarang $\boldsymbol{c}=\left(c_{0}, c_{1}, c_{2}, \ldots, c_{n-1}\right) \in C$. Dari (1), diperoleh $\pi(\boldsymbol{c})=\pi\left(c_{0}, c_{1}, c_{2}, \ldots, c_{n-1}\right)=c_{0}+$ $c_{1} x+c_{2} x^{2}+\cdots+c_{n-1} x^{n-1} \in \pi(C)$. Kemudian, $x \pi(\boldsymbol{c})=c_{0} x+c_{1} x^{2}+c_{2} x^{3}+\cdots+$ 
$c_{n-1} x^{n}=c_{n-1}+c_{0} x+c_{1} x^{2}+c_{2} x^{3}+\cdots+c_{n-1} x^{n}-c_{n-1}=c_{n-1}+c_{0} x+c_{1} x^{2}+$ $c_{2} x^{3}+\cdots+c_{n-1}\left(x^{n}-1\right)$. Karena $x^{n}-1=0$ di $F_{q}[x] /\left(x^{n}-1\right)$, maka diperoleh $x \pi(\boldsymbol{c})=c_{n-1}+c_{0} x+c_{1} x^{2}+c_{2} x^{3}+\cdots+c_{n-2} x^{n-1} \in \pi(C)$. Oleh karena itu, $\left(c_{n-1}, c_{0}, c_{1}, \ldots, c_{n-2}\right) \in C$. Jadi, $C$ adalah kode siklik.

$\Leftrightarrow)$ Misalkan $C$ adalah kode siklik.

(i) Ambil sebarang $\pi(\boldsymbol{d}), \pi(\boldsymbol{e}) \in \pi(C)$ dengan $\pi(\boldsymbol{d})=\pi\left(d_{0}, d_{1}, d_{2}, \ldots, d_{n-1}\right)=d_{0}+$ $d_{1} x+d_{2} x^{2}+\cdots+d_{n-1} x^{n-1}, \pi(\boldsymbol{e})=\pi\left(e_{0}, e_{1}, e_{2}, \ldots, e_{n-1}\right)=e_{0}+e_{1} x+e_{2} x^{2}+$ $\cdots+e_{n-1} x^{n-1}$ dan $\left(d_{0}, d_{1}, d_{2}, \ldots, d_{n-1}\right),\left(e_{0}, e_{1}, e_{2}, \ldots, e_{n-1}\right) \in C$. Akibatnya, $\pi(\boldsymbol{d})-\pi(\boldsymbol{e})=\left(d_{0}+d_{1} x+d_{2} x^{2}+\cdots+d_{n-1} x^{n-1}\right)-\left(e_{0}+e_{1} x+e_{2} x^{2}+\cdots+\right.$ $\left.e_{n-1} x^{n-1}\right)=\left(d_{0}-e_{0}\right)+\left(d_{1}-e_{1}\right) x+\left(d_{2}-e_{2}\right) x^{2}+\cdots+\left(d_{n-1}-e_{n-1}\right) x^{n-1}$. Karena $\left(e_{0}, e_{1}, e_{2}, \ldots, e_{n-1}\right) \in C$, maka $-\left(e_{0}, e_{1}, e_{2}, \ldots, e_{n-1}\right) \in C$. Dengan demikian, $\left(d_{0}, d_{1}, d_{2}, \ldots, d_{n-1}\right)+\left(-\left(e_{0}, e_{1}, e_{2}, \ldots, e_{n-1}\right)\right)=\left(d_{0}, d_{1}, d_{2}, \ldots, d_{n-1}\right)-$ $\left(e_{0}, e_{1}, e_{2}, \ldots, e_{n-1}\right)=\left(d_{0}-e_{0}, d_{1}-e_{1}, d_{2}-e_{2}, \ldots, d_{n-1}-e_{n-1}\right) \in C$. Oleh karena itu, $\pi(\boldsymbol{d})-\pi(\boldsymbol{e}) \in \pi(C)$.

(ii) Ambil sebarang $\pi(\boldsymbol{f}) \in \pi(C)$ dengan $\pi(\boldsymbol{f})=\pi\left(f_{0}, f_{1}, f_{2}, \ldots, f_{n-1}\right)=f_{0}+f_{1} x+$ $f_{2} x^{2}+\cdots+f_{n-1} x^{n-1}$ dan $\left(f_{0}, f_{1}, f_{2}, \ldots, f_{n-1}\right) \in C$. Akibatnya, $x \pi(\boldsymbol{f})=f_{n-1}+$ $f_{0} x+f_{1} x^{2}+\cdots+f_{n-2} x^{n-1}=\pi\left(f_{n-1}, f_{0}, f_{1}, \ldots, f_{n-2}\right) \in \pi(C)$ dan $x^{2} \pi(\boldsymbol{f})=$ $x(x \pi(\boldsymbol{f}))=f_{n-2}+f_{n-1} x+f_{0} x^{2}+\cdots+f_{n-3} x^{n-1}=\pi\left(f_{n-2}, f_{n-1}, f_{0}, \ldots, f_{n-3}\right) \in$ $\pi(C)$. Dengan demikian, berdasarkan induksi, diperoleh $x^{i} \pi(\boldsymbol{f}) \in \pi(C)$ dengan $i \geq$ 0 . Oleh karena itu, untuk setiap $h(x)=h_{0}+h_{1} x+h_{2} x^{2}+\cdots+h_{n-1} x^{n-1} \in$ $F_{q}[x] /\left(x^{n}-1\right)$, diperoleh $h(x) \pi(\boldsymbol{f})=\sum_{i=0}^{n-1} h_{i}\left(x^{i} \pi(\boldsymbol{f})\right) \in \pi(C)$ dan $\pi(\boldsymbol{f}) h(x)=$ $\sum_{i=0}^{n-1}\left(x^{i} \pi(\boldsymbol{f})\right) h_{i} \in \pi(C)$.

Jadi, $\pi(C)$ adalah ideal dari $F_{q}[x] /\left(x^{n}-1\right)$.

Contoh 4.2 (i) $C=\{000,111,222\}$ adalah kode siklik 3-ary, maka $\pi(C)=$ $\left\{0,1+x+x^{2}, 2+2 x+2 x^{2}\right\}$ adalah ideal dari $F_{3}[x] /\left(x^{3}-1\right)$.

(ii) $I=\left\{0,1+x^{2}, x+x^{3}, 1+x+x^{2}+x^{3}\right\}$ adalah ideal dari $F_{2}[x] /\left(x^{4}-1\right)$, maka $\pi^{-1}(I)=\{0000,1010,0101,1111\}$ adalah kode siklik 2-ary.

\section{Sifat-Sifat Polinomial Pembangun dari Ideal dan Dimensi dari Kode Siklik}

Teorema 5.1 Misalkan $I$ adalah ideal tak nol di $F_{q}[x] /\left(x^{n}-1\right)$. Maka $g(x)$ adalah polinomial monik dengan derajat terkecil di $I$ jika dan hanya jika $g(x)$ adalah polinomial pembangun dari $I$.

Bukti. $(\Longrightarrow)$ Misalkan $g(x)$ adalah polinomial monik dengan derajat terkecil di $I$. Ambil sebarang $f_{1}(x) \in I$, maka berdasarkan algoritma pembagian, terdapat dengan tunggal $s(x), r(x) \in F_{q}[x] /\left(x^{n}-1\right)$ sehingga $f_{1}(x)=s(x) g(x)+r(x)$ dengan $\operatorname{deg}(r(x))<\operatorname{deg}(g(x))$ atau $r(x)=0$. Akibatnya, $r(x)=f_{1}(x)-s(x) g(x)$ 
sehingga $r(x) \in I$. Karena $g(x)$ adalah polinomial monik dengan derajat terkecil di $I$, maka $r(x)=0$. Oleh karena itu, $f_{1}(x)=s(x) g(x)$. Jadi, $g(x)$ adalah polinomial pembangun dari $I$.

$(\Longleftarrow)$ Misalkan $g(x)$ adalah polinomial pembangun dari $I$. Ambil sebarang $f_{2}(x) \in I$ dengan $f_{2}(x)=h(x) g(x)$ dan $h(x) \in F_{q}[x] /\left(x^{n}-1\right)$. Akibatnya, $\operatorname{deg}(g(x)) \leq$ $\operatorname{deg}\left(f_{2}(x)\right)$. Jadi, $g(x)$ adalah polinomial monik dengan derajat terkecil di $I$.

Teorema 5.2 Misalkan $I$ adalah ideal tak nol di $F_{q}[x] /\left(x^{n}-1\right)$, maka terdapat dengan tunggal polinomial pembangun dari $I$.

Bukti. Karena $F_{q}[x] /\left(x^{n}-1\right)$ adalah ring ideal utama, maka $I$ adalah ideal utama, yaitu terdapat $g(x) \in I$ sebagai polinomial pembangun dari $I$. Selanjutnya, misalkan $g_{1}(x)$ dan $g_{2}(x)$ adalah polinomial pembangun dari $I$ dengan $g_{1}(x) \neq g_{2}(x)$. Berdasarkan Teorema 5.1, $g_{1}(x)$ dan $g_{2}(x)$ adalah polinomial monik dengan derajat terkecil di $I$ sehingga $\operatorname{deg}\left(g_{1}(x)\right)=\operatorname{deg}\left(g_{2}(x)\right)$. Akibatnya, terdapat $\alpha \in F_{q}$ sehingga $\alpha\left(g_{1}(x)-g_{2}(x)\right)$ juga polinomial monik di $I$ dengan $\operatorname{deg}\left(\alpha\left(g_{1}(x)-\right.\right.$ $\left.\left.g_{2}(x)\right)\right)<\operatorname{deg}\left(g_{1}(x)\right)=\operatorname{deg}\left(g_{2}(x)\right)$. Hal ini menimbulkan kontradiksi. Oleh karena itu, $g_{1}(x)=g_{2}(x)$. Jadi, terdapat dengan tunggal polinomial pembangun dari $I$.

Teorema 5.3 Misalkan $I$ adalah ideal tak nol di $F_{q}[x] /\left(x^{n}-1\right)$. Maka $g(x)$ adalah polinomial pembangun dari $I$ jika dan hanya $g(x)$ adalah pembagi monik dari $x^{n}-1$.

Bukti. $(\Rightarrow)$ Misalkan $g(x)$ adalah polinomial pembangun dari $I$. Maka berdasarkan algoritma pembagian, terdapat dengan tunggal $s_{1}(x), r_{1}(x) \in F_{q}[x] /\left(x^{n}-1\right)$ sehingga $x^{n}-1=s_{1}(x) g(x)+r_{1}(x)$ dengan $\operatorname{deg}\left(r_{1}(x)\right)<\operatorname{deg}(g(x))$ atau $r_{1}(x)=0$. Akibatnya, $r_{1}(x)=\left(x^{n}-1\right)-s_{1}(x) g(x)$ sehingga $r_{1}(x) \in I$. Karena $g(x)$ adalah polinomial pembangun dari $I$, maka berdasarkan Teorema 5.1, $g(x)$ adalah polinomial monik dengan derajat terkecil di $I$. Oleh karena itu, $r_{1}(x)=0$ sehingga $x^{n}-1=s_{1}(x) g(x)$. Jadi, $g(x)$ adalah pembagi monik dari $x^{n}-1$.

$(\Leftarrow)$ Misalkan $g(x)$ adalah pembagi monik dari $x^{n}-1$. Asumsikan $h(x)$ adalah polinomial pembangun dari $I$. Maka terdapat $s_{2}(x) \in F_{q}[x] /\left(x^{n}-1\right)$ sehingga $h(x) \equiv s_{2}(x) g(x)\left(\bmod x^{n}-1\right)$. Akibatnya, $g(x)$ membagi $h(x)$. Selanjutnya, berdasarkan Teorema 5.1, $h(x)$ adalah polinomial monik dengan derajat terkecil di $I$. Oleh karena itu, $g(x)=h(x)$. Jadi, $g(x)$ adalah polinomial pembangun dari $I$.

Contoh 5.4 (i) $I_{1}=\left\{0,1+x+x^{2}, 2+2 x+2 x^{2}\right\}$ adalah ideal dari $F_{3}[x] /\left(x^{3}-1\right)$ dan $1+x+x^{2}$ adalah polinomial monik dengan derajat terkecil di $I_{1}$, maka $1+$ $x+x^{2}$ adalah polinomial pembangun dari $I_{1}$ dan pembagi monik dari $x^{3}-1$. 
(ii) $I_{2}=\left\{0,1+x^{2}, x+x^{3}, 1+x+x^{2}+x^{3}\right\}$ adalah ideal dari $F_{2}[x] /\left(x^{4}-1\right)$ dan $1+x^{2}$ adalah polinomial monik dengan derajat terkecil di $I_{2}$, maka $1+x^{2}$ adalah polinomial pembangun dari $I_{2}$ dan pembagi monik dari $x^{4}-1$.

Teorema 5.5 Misalkan $I$ adalah ideal di $F_{q}[x] /\left(x^{n}-1\right)$ dan $g(x)$ adalah polinomial pembangun dari $I$. Jika $g(x)$ berderajat $n-k$, maka kode siklik yang bersesuaian berdimensi $k$.

Bukti. Didefinisikan $A:=\left\{g(x) f(x): f(x) \in F_{q}[x] /\left(x^{n}-1\right), \operatorname{deg}(f(x)) \leq k-1\right\}$. Diperoleh $A \subseteq<g(x)>$. Selanjutnya, ambil sebarang $g(x) h(x) \in\langle g(x)\rangle$ dengan $h(x) \in F_{q}[x] /\left(x^{n}-1\right)$, maka berdasarkan algoritma pembagian terdapat dengan tunggal $s(x), r(x) \in I$ sehingga $g(x) h(x)=s(x)\left(x^{n}-1\right)+r(x)$ dengan $\operatorname{deg}(r(x))<n$. Kemudian, diperoleh $r(x)=g(x) h(x)-s(x)\left(x^{n}-1\right)$. Karena $x^{n}-$ $1=0$ di $F_{q}[x] /\left(x^{n}-1\right)$, maka $r(x)=g(x) h(x)$. Akibatnya, karena $\operatorname{deg}(g(x))=$ $n-k$, maka $\operatorname{deg}(h(x))<k$. Oleh karena itu, $r(x)=g(x) h(x) \in A$. Hal ini menunjukkan bahwa $\langle g(x)\rangle \subseteq A$. Dengan demikian, $A=\langle g(x)\rangle$. Di sisi lain, karena $\left|F_{q}\right|=q$, maka terdapat $q$ pilihan untuk setiap $f(x)$ dengan $\operatorname{deg}(f(x)) \leq k-1$. Akibatnya, $|A|=q^{k}$. Jadi, berdasarkan Teorema 3.4, dimensi dari kode siklik yang bersesuaian adalah $\log _{q}|A|=\log _{q} q^{k}=k$.

Contoh 5.6 Tabel $1-4$ berikut menunjukkan faktorisasi dari $x^{n}-1$, polinomial pembangun dan derajatnya, kode siklik $q$-ary dengan $q=2,3,4,5$ beserta dimensinya.

Tabel 1 Kode siklik 2-ary dengan $n \leq 5$.

\begin{tabular}{|c|c|c|c|c|c|}
\hline \multirow{n}{*}{$n$} & $\begin{array}{c}\text { Faktorisasi } \\
\boldsymbol{x}^{\boldsymbol{n}}-\mathbf{1}\end{array}$ & $\begin{array}{c}\text { Polinomial } \\
\text { Pembangun } \\
(\boldsymbol{g}(\boldsymbol{x}))\end{array}$ & $\operatorname{deg}(\boldsymbol{g}(\boldsymbol{x}))$ & $\operatorname{Kode~Siklik}(\boldsymbol{C})$ & $\operatorname{dim}(\boldsymbol{C})$ \\
\hline \multirow{2}{*}{1} & $1+x$ & 1 & 0 & $\mathbb{Z}_{2}$ & 1 \\
\hline \multirow{3}{*}{2} & \multirow{3}{*}{$(1+x)^{2}$} & $1+x$ & 1 & $\{0\}$ & 0 \\
\cline { 3 - 6 } & & 1 & 0 & $\mathbb{Z}_{2}^{2}$ & 2 \\
\cline { 3 - 6 } & & $(1+x)^{2}$ & 2 & $\{00,11\}$ & 1 \\
\hline \multirow{3}{*}{3} & $(1+x)$ & 1 & 0 & $\{00\}$ & 0 \\
\cline { 3 - 6 } & \multirow{2}{*}{$\left(1+x+x^{2}\right)$} & $1+x+x^{2}$ & 2 & $\{000,110,011,101\}$ & 2 \\
\cline { 3 - 6 } & & $(1+x)$ & 3 & $\{00,111\}$ & 1 \\
\cline { 3 - 6 } & & $\left(1+x+x^{2}\right)$ & 3 & $\{000\}$ & 0 \\
\hline
\end{tabular}




\begin{tabular}{|c|c|c|c|c|c|}
\hline \multirow{5}{*}{4} & \multirow{5}{*}{$(1+x)^{4}$} & 1 & 0 & $\mathbb{Z}_{2}^{4}$ & 4 \\
\hline & & $1+x$ & 1 & $\begin{array}{c}\{0000,1100,0110 \\
0011,1001,1010 \\
0101,1111\}\end{array}$ & 3 \\
\hline & & $(1+x)^{2}$ & 2 & $\begin{array}{l}\{0000,1010 \\
0101,1111\}\end{array}$ & 2 \\
\hline & & $(1+x)^{3}$ & 3 & $\{0000,1111\}$ & 1 \\
\hline & & $(1+x)^{4}$ & 4 & $\{0000\}$ & 0 \\
\hline \multirow{4}{*}{5} & \multirow{4}{*}{$\begin{array}{c}(1+x) \\
\left(1+x+x^{2}\right. \\
\left.+x^{3}+x^{4}\right)\end{array}$} & 1 & 0 & $\mathbb{Z}_{2}^{5}$ & 5 \\
\hline & & $1+x$ & 1 & $\begin{array}{c}\{00000,11000, \\
01100,00110, \\
00011,10001, \\
10100,01010, \\
00101,10010, \\
01001,11110, \\
01111,10111, \\
11011,11101\}\end{array}$ & 4 \\
\hline & & $\begin{array}{l}1+x+x^{2} \\
+x^{3}+x^{4}\end{array}$ & 4 & $\{00000,11111\}$ & 1 \\
\hline & & $\begin{array}{c}(1+x) \\
\left(1+x+x^{2}\right. \\
\left.+x^{3}+x^{4}\right)\end{array}$ & 5 & $\{00000\}$ & 0 \\
\hline
\end{tabular}

Tabel 2 Kode siklik 3-ary dengan $n \leq 3$.

\begin{tabular}{|c|c|c|c|c|c|}
\hline$n$ & $\begin{array}{c}\text { Faktorisasi } \\
\qquad x^{n}-1\end{array}$ & $\begin{array}{c}\text { Polinomial } \\
\text { Pembangun } \\
(g(x))\end{array}$ & $\operatorname{deg}(g(x))$ & Kode Siklik $(C)$ & $\operatorname{dim}(C)$ \\
\hline \multirow{2}{*}{1} & \multirow{2}{*}{$2+x$} & 1 & 0 & $\mathbb{Z}_{3}$ & 1 \\
\hline & & $2+x$ & 1 & $\{0\}$ & 0 \\
\hline \multirow{4}{*}{2} & \multirow{4}{*}{$\begin{array}{l}(1+x) \\
(2+x)\end{array}$} & 1 & 0 & $\mathbb{Z}_{3}^{2}$ & 2 \\
\hline & & $1+x$ & 1 & $\{00,11,22\}$ & 1 \\
\hline & & $2+x$ & 1 & $\{00,21,12\}$ & 1 \\
\hline & & $\begin{array}{l}(1+x) \\
(2+x)\end{array}$ & 2 & $\{00\}$ & 0 \\
\hline \multirow{4}{*}{3} & \multirow{4}{*}{$(2+x)^{3}$} & 1 & 0 & $\mathbb{Z}_{3}^{3}$ & 3 \\
\hline & & $2+x$ & 1 & $\{000,210,120\}$ & 2 \\
\hline & & $(2+x)^{2}$ & 2 & $\{000,111,222\}$ & 1 \\
\hline & & $(2+3)^{3}$ & 3 & $\{000\}$ & 0 \\
\hline
\end{tabular}


Tabel 3 Kode siklik 4-ary dengan $n \leq 3$.

\begin{tabular}{|c|c|c|c|c|c|}
\hline$n$ & $\begin{array}{c}\text { Faktorisasi } \\
\qquad x^{n}-1\end{array}$ & $\begin{array}{l}\text { Polinomial } \\
\text { Pembangun } \\
(g(x))\end{array}$ & $\operatorname{deg}(g(x))$ & Kode Siklik $(C)$ & $\operatorname{dim}(C)$ \\
\hline \multirow{2}{*}{1} & \multirow{2}{*}{$3+x$} & 1 & 0 & $\mathbb{Z}_{4}$ & 1 \\
\hline & & $3+x$ & 1 & $\{0\}$ & 0 \\
\hline \multirow{4}{*}{2} & \multirow{4}{*}{$\begin{array}{l}(1+x) \\
(3+x)\end{array}$} & 1 & 0 & $\mathbb{Z}_{4}^{2}$ & 2 \\
\hline & & $1+x$ & 1 & $\{00,11,22,33\}$ & 1 \\
\hline & & $3+x$ & 1 & $\{00,31,13,22\}$ & 1 \\
\hline & & $\begin{array}{l}(1+x) \\
(3+x)\end{array}$ & 2 & $\{00\}$ & 0 \\
\hline \multirow{4}{*}{3} & \multirow{4}{*}{$\begin{array}{c}(3+x) \\
\left(1+x+x^{2}\right)\end{array}$} & 1 & 0 & $\mathbb{Z}_{4}^{3}$ & 3 \\
\hline & & $3+x$ & 1 & $\begin{array}{l}\{000,310,031,103, \\
301,130,013,211, \\
121,112,022,202, \\
220,323,332,233\}\end{array}$ & 2 \\
\hline & & $1+x+x^{2}$ & 2 & $\{000,111,222,333\}$ & 1 \\
\hline & & $\begin{array}{c}(3+x) \\
\left(1+x+x^{2}\right)\end{array}$ & 3 & $\{000\}$ & 0 \\
\hline
\end{tabular}

Tabel 4 Kode siklik 5-ary dengan $n \leq 3$.

\begin{tabular}{|c|c|c|c|c|c|}
\hline $\boldsymbol{n}$ & $\begin{array}{c}\text { Faktorisasi } \\
x^{n}-1\end{array}$ & $\begin{array}{l}\text { Polinomial } \\
\text { Pembangun } \\
(g(x))\end{array}$ & $\operatorname{deg}(g(x))$ & Kode Siklik $(C)$ & $\operatorname{dim}(C)$ \\
\hline \multirow{2}{*}{1} & \multirow{2}{*}{$4+x$} & 1 & 0 & $\mathbb{Z}_{5}$ & 1 \\
\hline & & $4+x$ & 1 & $\{0\}$ & 0 \\
\hline \multirow{4}{*}{2} & \multirow{4}{*}{$\begin{array}{l}(1+x) \\
(4+x)\end{array}$} & 1 & 0 & $\mathbb{Z}_{5}^{2}$ & 2 \\
\hline & & $1+x$ & 1 & $\{00,11,22,33,44\}$ & 1 \\
\hline & & $4+x$ & 1 & $\{00,41,14,32,23\}$ & 1 \\
\hline & & $\begin{array}{l}(1+x) \\
(4+x)\end{array}$ & 2 & $\{00\}$ & 0 \\
\hline \multirow[b]{2}{*}{3} & \multirow[b]{2}{*}{$\begin{array}{c}(4+x) \\
\left(1+x+x^{2}\right)\end{array}$} & 1 & 0 & $\mathbb{Z}_{5}^{3}$ & 3 \\
\hline & & $4+x$ & 1 & $\begin{array}{c}000,410,041, \\
104,140,014 \\
401,212,221 \\
122,320,032 \\
203,230,023 \\
302,113,311 \\
131,442,244 \\
424,433,343,334\}\end{array}$ & 2 \\
\hline
\end{tabular}




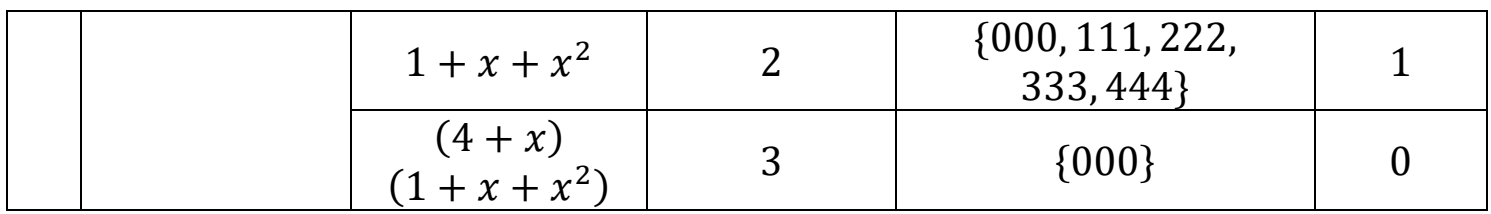

\section{Kesimpulan}

Kesimpulan dari penelitian ini adalah sebagai berikut :

1. Hubungan antara ideal dan kode siklik adalah himpunan bagian tak kosong $C$ dari $F_{q}^{n}$ adalah kode siklik jika dan hanya jika $\pi(C)$ adalah ideal di $F_{q}[x] /\left(x^{n}-1\right)$.

2. Sifat-sifat polinomial pembangun dari ideal dan dimensi dari kode siklik adalah :

a. Polinomial $g(x)$ adalah polinomial monik dengan derajat terkecil di ideal tak nol $I$ dari $F_{q}[x] /\left(x^{n}-1\right)$ jika dan hanya jika $g(x)$ adalah polinomial pembangun dari $I$.

b. Terdapat dengan tunggal polinomial pembangun dari ideal tak nol $I$ dari $F_{q}[x] /\left(x^{n}-1\right)$.

c. Polinomial $g(x)$ adalah polinomial pembangun dari ideal tak nol $I$ dari $F_{q}[x] /\left(x^{n}-1\right)$ jika dan hanya jika $g(x)$ adalah pembagi monik dari $x^{n}-1$.

d. Jika polinomial pembangun dari ideal tak nol $I$ dari $F_{q}[x] /\left(x^{n}-1\right)$ berderajat $n-k$, maka kode siklik yang bersesuaian berdimensi $k$.

\section{$7 \quad$ Daftar Pustaka}

[1] Hankerson, D.R., Horman, D.G., Leonard, D.A., Lindner, C.C., Phelps, K.T., Rodger, C.A. \& Wall, J.R., 2000, Coding Theory and Cryptography: The Essentials Second Edition, Marcel Dekker, Inc.

[2] Ling, S. \& Xing, C., 2004, Coding Theory A First Course, Cambridge University Press, hal 133.

[3] Prange, E., 1957, Cyclic Error-Correcting Codes in Two Symbols, AFCRC-TN57, hal. 103.

[4] Shannon, C.E., 1948, A Mathematical Theory of Communication, Bell System Technical Journal, Vol. 27, hal. 379-423, 623-656. 